\title{
A Regional Analysis of the Earnings of Immigrants
}

\author{
Don Bellante and Carl A. Kogut*
}

\begin{abstract}
Data from the 1990 Census One Percent Public Use Microdata Sample are examined in order to determine the extent of regional differences in the earnings of immigrants relative to nonimmigrants of the same ethnic origin and relative to nonimmigrants of Western European origin. Earnings equations are separately estimated for eight regions as well as for the U.S. as a whole. Also, relative earnings ratios are separately estimated for each of six ethnic groups within each region. The regional earnings functions are found to be statistically significantly different from a function estimated for the U.S. as a whole.
\end{abstract}

\section{INTRODUCTION}

The relative earnings of immigrants to the U.S. has long been a subject of considerable interest in the economics literature, but the level of interest has increased dramatically in recent years as public policy issues have come to the forefront. For example, recent welfare reform makes a distinction between citizens and noncitizens and has renewed debate on the burden of immigrants on the various social services provided by state and federal agencies. Moreover, there is an ongoing debate as to whether immigrants contribute more or less tax revenues to social services than they cost. ${ }^{1}$ Borjas (1994b) provides an extensive review of this empirical literature. While many empirical studies of the earnings of immigrants involve equations that include one or more regional dummy variables as control variables, only a few (discussed below) have focused on a detailed analysis of regional earnings differences. If one took the simplest theoretical models as definitive, regional differences wouldn't be expected to exist, as the internal migration of immigrants would tend to eliminate serious regional differences in the relative earnings of those immigrants. But there is ample evidence that this tendency may be thwarted. First, immigrants tend to enter through a very limited number of "ports of entry." Zavodny (1998) reports that between 1989 and 1994 two-thirds of all new immigrants to the U.S. resided in only four states: California, New York, Texas, and Florida. Specific ethnic groups may be even more concentrated. For example, the overwhelming majority of Cuban immigrants are located in Florida, New York, and New Jersey. Second, and more importantly, Bartel and Koch (1991) find that immigrants tend to locate where concentrations of other, similar immigrants are found, and they do not tend to disperse in response to regional economic

*Professor of Economics, University of South Florida, Tampa, FL; and Associate Professor of Economics, Northeast Louisiana University, Monroe, LA. The authors wish to thank Henry W. Herzog, Jr., Ernest P. Goss, and three anonymous referees for helpful comments. The work of Don Bellante was supported by a grant from the John M. Olin Institute for Employment Practice and Policy and a grant from the Division of Sponsored Research of the University of South Florida. The authors alone are responsible for the contents.

${ }^{1}$ On this matter, see the exchange between Simon $(1989,1996)$ and Borjas $(1991,1996)$. 
differentials as does the population as a whole. ${ }^{2}$ Such research reveals that, if anything, the internal migration of immigrants is toward areas where they are already concentrated.

While there have been several previous studies of the earnings of immigrants that have employed regional dummy variables within a wage equation in order to control for region effects, only a few have been concerned primarily with regional earnings differences. The regional breakdown ranges from two regions, i.e., North and South (Daneshvary and Weber 1991), to four (Daneshvary 1993). No regional analysis has as yet been published that utilizes the most recently available Census data.

The present study seeks to complement the existing literature in several ways. First, this study examines the earnings of immigrants relative to native-born Americans of the same ethnic background as well as relative to the majority group, native-born Americans of Western European ancestry. Second, the study is conducted for eight regions (as well as the U.S. as a whole) using separate regressions for each region. Unlike previous studies that employ a set of regional dummy variables that are not interacted with all other variables, the modeling of each region separately is less subject to specification error in measuring regional differences. Third, this study uses the 1990 Census One Percent Public Use Microdata Sample. As will be seen below, substantial and significant interregional variations are found, underscoring the value of regional disaggregation in relative earnings studies.

\section{METHOD}

The U.S. is divided into eight regions as described in Table 1. The regional categories were devised by the authors so as to include contiguous states and have a substantial number of immigrants.

TABLE 1

Regions of the U.S.

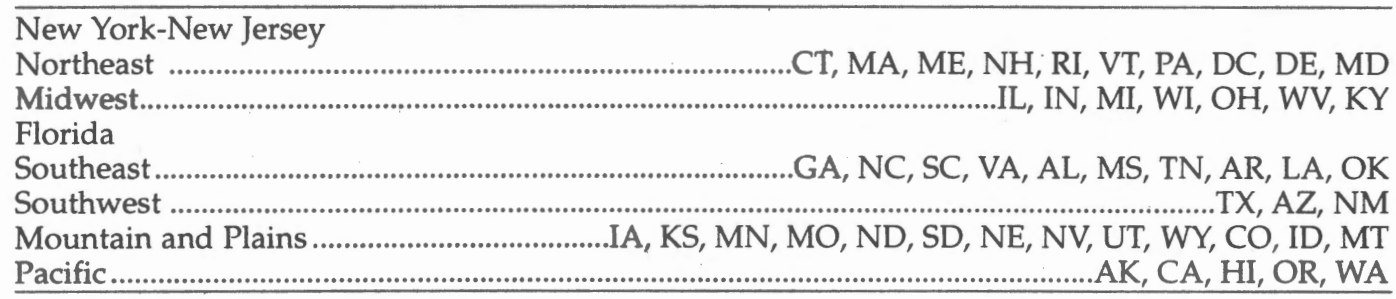

We employ a variant of the standard human capital type of wage equation supplemented by variables or groups of variables that account for time in the U.S., region of ancestry, immigration status, and age at immigration. Also included are variables that interact immigration status with region of ancestry and years of schooling, and a variable that interacts age at immigration with time in the U.S. Further, years of schooling in the U.S. is a separate variable from schooling estimated to have been obtained abroad. Because the intermittent labor force participation of ${ }^{2}$ See also Dunlevy (1991). 
females diminishes the ability to proxy experience with age, this study, as is common to those using Census data, limits its domain to males.

The equation estimated is as follows:

$$
\begin{aligned}
\ln W= & a+b_{1} \text { IM }+b_{2} \text { MARRIED }+b_{3} \text { AGEATIM }+b_{4} \text { AGEATIM }{ }^{2}+b_{5} \text { YEARSUS } \\
& +b_{6} \text { YEARSUS }^{2}+b_{7} \text { AGEATIM*YEARSUS }+b_{8} \text { FORED }+b_{9} \text { USED } \\
& +b_{10} \text { USED }^{*} \text { IM }+b_{11} \text { ANC1 }+b_{12} \text { ANC2 }+b_{13} \text { ANC3 }+b_{14} \text { ANC4 } \\
& +b_{15} \text { ANC }+b_{16} \text { ANC1*IM }+b_{17} \text { ANC2 }{ }^{*} \text { IM }+b_{18} \text { ANC }{ }^{*} \text { IM } \\
& +b_{19} \text { ANC4 }{ }^{*} \text { IM }+b_{20} \text { ANC5*IM }+e .
\end{aligned}
$$

The variables are defined as follows:

$\ln W=\log$ of the hourly wage.

$\mathrm{IM}=$ a dummy variable equal to 1 if the individual is an immigrant.

MARRIED = a dummy variable equal to 1 if married, spouse present.

AGEATIM = age of the individual at the time of immigration, set to 0 for a nonimmigrant.

AGEATIM $^{2}=$ the square of age at immigration.

YEARSUS $=$ The number of years residing in the U.S. For immigrants, this is their age minus AGEATIM. For nonimmigrants, it is their age. YEARSUS ${ }^{2}$ is the square of this variable.

AGEATIM $^{*}$ YEARSUS $=$ a variable interacting AGEATIM and YEARSUS.

FORED $=$ the number of years of education estimated to have been obtained before immigration to the U.S.

USED $=$ the number of years of education obtained in the U.S. ${ }^{3}$

USED*IM = a dummy variable interacting USED and IM.

ANC1 to ANC5 = equal a set of dummy variables designating area of ancestry of all individuals (whether immigrant or not) as follows: Ancestry from Western Europe formed the omitted category; $\mathrm{ANC1}=1$ for Eastern Europe and the Soviet Union; ANC2 = 1 for Hispanic area ancestry; ANC3 = 1 for African-American and Sub-Sahara Africa, West Indies, and non-Hispanic Central and South America (hereafter for convenience referred to as African); ANC $4=1$ for North Africa and Southwest Asia (hereafter for convenience referred to as Arabic); $A N C 5=1$ for Asia. ANC $1{ }^{*} \mathrm{IM}$ to $\mathrm{ANC}{ }^{*} \mathrm{IM}=$ a set of dummy terms interacting immigrant status and ANC1 through ANC5, respectively.

\section{DATA}

The source of data is individual observations from the person files of the 1990 Census One Percent Public Use Microdata Sample. The study sample is

${ }^{3}$ The Census does not record where education is received. Therefore, we estimated the value of FORED for immigrants by taking into account their age at immigration and then the likely years of schooling they would have completed if they followed a typical U.S. pattern. For example, an individual who entered the U.S. at age 18 was assumed to have completed 12 years of school, if he reported having at least 12 years of schooling. USED would be valued at the remaining years of schooling reported by the immigrant. For nonimmigrants, FORED is by definition zero and USED is equal to the number of reported years of schooling. To the extent that immigration or other factors interrupt schooling, our method may overestimate FORED. While this method is rough, the results reported below seem reasonable. 
limited to males between the ages of 25 through 64 . A number of other exclusions also were imposed on the data. The sample excludes individuals living in institutions or group quarters, as well as those in the military. Individuals who were selfemployed or working without pay in a family business also were excluded. ${ }^{4}$ Those who worked less than 27 weeks in 1989 were excluded, as were those who were currently enrolled in school if they worked less than 50 weeks. In order to eliminate the most egregious outliers, observations were eliminated if their hourly wage was calculated to be less than $\$ 1.00$ per hour or greater than $\$ 250.00$ per hour. These types of data restrictions are common to earnings studies in general, as well as those dealing specifically with immigrants. ${ }^{5}$

Our methodology suggested other restrictions that should be applied. An aim of this study is to compare earnings of immigrants to nonimmigrants of similar ethnic origin. Therefore, individuals designating their ancestry as American Indian, Aleut, or Eskimo were excluded. Also excluded were all individuals who did not unambiguously categorize themselves in one and only one of the ancestry categories (which are not mutually exhaustive) defined above. ${ }^{6}$ Our various filters resulted in a final sample of 212,783 males, of whom 24,377 , or 11.5 percent, were immigrants. Table 2 presents the mean characteristics of both the immigrant and nonimmigrant samples for the entire U.S.

TABLE 2

Independent Variable Means

\begin{tabular}{lcc}
\hline Variable & Immigrant Means & Nonimmigrant Means \\
\hline IM & 1 & 0 \\
MARRIED & 0.707 & 0.718 \\
AGEATIM & 24.5 & 0 \\
AGEATIM & & 0 \\
YEARSUS & 721.0 & 40.8 \\
YEARSUS & 16.3 & $1,770.0$ \\
AGEATIM*YEARSUS & 385.1 & 0 \\
FORED & 334.3 & 0 \\
USED & 10.5 & 13.3 \\
USED*IM & 1.8 & 0 \\
ANC0 (omitted category) [W. Eur.] & 1.8 & 0.792 \\
ANC1 [E. Eur.-Sov.] & 0.227 & 0.074 \\
ANC2 [Hispanic] & 0.072 & 0.020 \\
ANC3 [African] & 0.276 & 0.104 \\
ANC4 [Arabic] & 0.081 & 0.002 \\
ANC5 [Asian] & 0.054 & 0.008 \\
& 0.290 & 188,406
\end{tabular}

Note: The values of ANCO*IM through ANC5*IM are not shown as they equal zero for nonimmigrants and are equal to the respective values of ANCO-ANC5 for immigrants.

${ }^{4}$ Every study of which we are aware eliminates self-employed individuals, most likely because of the fact that self-employed income mixes labor and capital returns. While beyond the scope of this paper, a separate comparison of self-employed natives and immigrants might provide interesting insights.

In particular, see Borjas (1994a).

${ }^{6}$ The major impact of limiting the study to these six ancestry categories is to exclude Canadians and those in the category the Census labels as Pacific (composed in large measure of immigrants who state their ancestry as Australia and New Zealand), a group that arguably should be excluded because of the potentially distorting effects from the extreme ethnic heterogeneity of this area. 
In two demographic respects the sample of immigrants is very similar to the nonimmigrants: the average age of both groups is about 41 , while 70.7 percent of immigrants and 71.8 percent of nonimmigrants are married with spouse present. To varying degrees, the two samples differ in other respects. For example, immigrants have one less year of total schooling, on average, than nonimmigrants (12.3 versus 13.3 years). Not surprisingly, the two samples differ most with respect to ancestry. Whereas the largest number by far of nonimmigrants trace their ancestry to Western Europe, the omitted category in Equation 1 (about 79 percent), Western Europeans make up less than 23 percent of the immigrants. The majority of immigrants are Hispanic or Asian. ${ }^{7}$

\section{RESULTS}

The results of the regressions estimated for the U.S. and each of its regions are presented in Table 3. Because of the various interaction terms involving immigrants, many of the coefficients by themselves do not have a straightforward interpretation. Nonetheless, a few simple conclusions do emerge. For one, marital status seems to have approximately the same positive effect on earnings across all regions. ${ }^{8}$

More interesting are the variables that permit comparisons between immigrants and the native born, such as those pertaining to education levels. Recall that education estimated to have been obtained abroad (FORED) is distinguished from education estimated to have been obtained in the U.S. (USED). Focusing on the U.S. as a whole, the marginal return to a year of foreign schooling is about 6.1 percent. The marginal return to a year of U.S. schooling is about 9.9 percent for the native born ${ }^{9}$ and about 7.4 percent (the sum of the coefficients of USED and USED*IM) for immigrants. Consideration of the coefficient values of ANC1ANC5 for the U.S. reveals that among the native born, only African ancestry individuals earn significantly less than otherwise comparable natives of Western European ancestry. Asian ancestry native born earn about 3.3 percent more than comparable natives of Western European ancestry, although, owing to the smaller sample sizes, the coefficient is not statistically significant in any of the separate region regressions. Arabic ancestry native born also earn significantly more than

\footnotetext{
${ }^{7}$ It should be noted that both the immigrant and nonimmigrant samples may be unrepresentative. Note that the sample of nonimmigrants in some ancestry categories may be particularly unrepresentative, owing to nonresponses and ambiguous responses to the Census question on ancestry. For example, the number of nonimmigrants who categorize themselves as Hispanic is surprisingly small ( 2 percent). Nonetheless, the youngest of this sample would have been born in 1964, obviously of parents who immigrated (or whose ancestors immigrated) before that year. However, prior to the liberalization of immigration in the $1960 \mathrm{~s}$, immigration from Latin America, particularly Mexico, was a small fraction of what it has been since then. Combined with the effect of eliminating those native born who list more than one ancestry category, nonimmigrants make up a smaller portion of our total sample than they do of the population at large. The immigrant group is probably much more representative, except for Hispanics. While the Census Bureau attempts to enumerate all, it is highly likely that illegal immigrants are very much undercounted, and it is most likely that they are overwhelmingly of Latin American origin.

${ }^{8} \mathrm{~A}$ version of Equation 1 including a term interacting marital status and immigrant status also was estimated. The interaction term was not significant and had a t-ratio of about 0.7 .

${ }^{9}$ It is assumed that the education of native-born Americans was obtained entirely in the U.S. The estimated coefficient of USED is within the range of earlier studies of the return to education (c.f. Smith and Welch 1989; Bellante and Kogut 1996).
} 
疍 行 สู่นุ้า $\sum^{5}$

彳ิ่

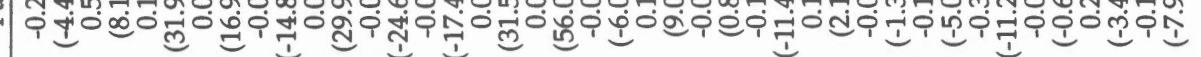

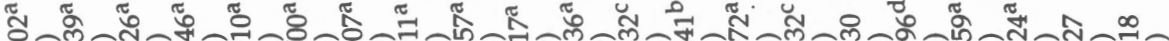

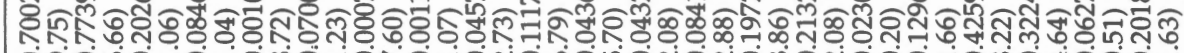

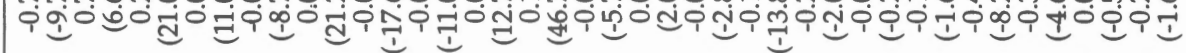

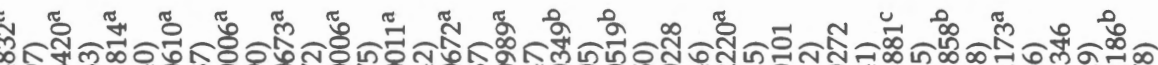

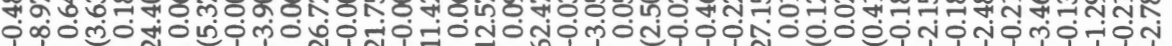

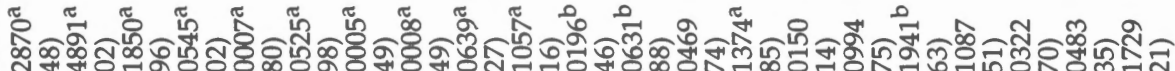
平 耳ै

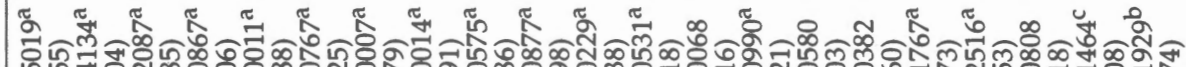

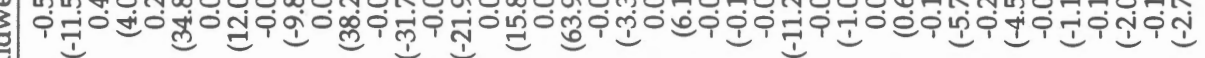

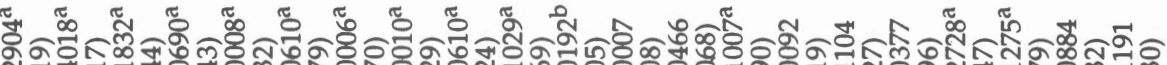

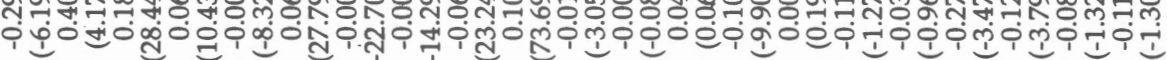

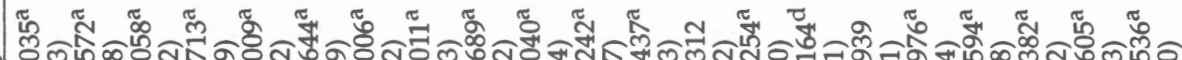
₹

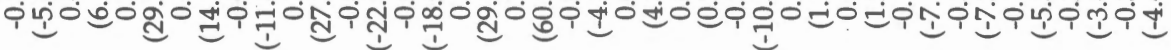

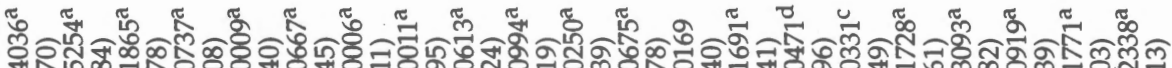

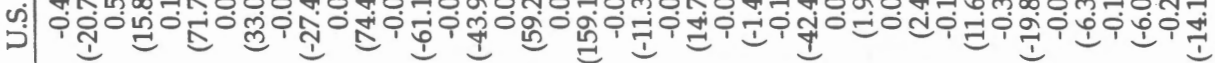
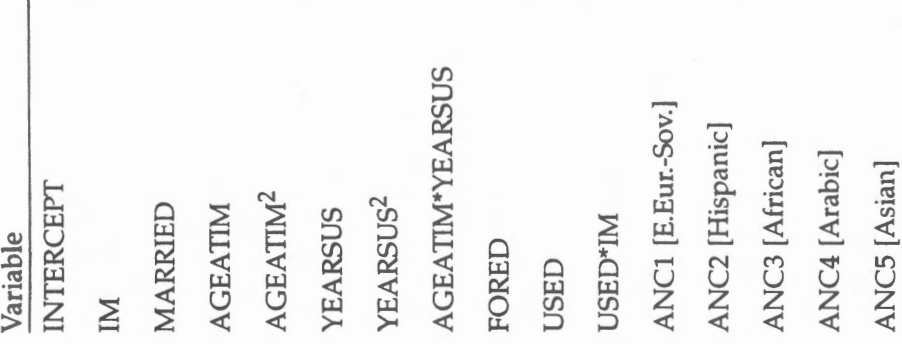
natives of Western European ancestry for the U.S. as a whole, but the difference is barely significant at the 0.10 level. The problem of aggregating across regions is illustrated very clearly when the earnings differentials of Arabic ancestry native born are examined separately by region. As can be seen in Table 3, the coefficients for ANC4 indicate a range of earnings differentials, from a statistically significant positive difference of nearly 12 percent to a significant negative difference of over 21 percent. However, except for the coefficients dealing with ancestry, the other coefficients do not vary dramatically across regions. Regional differences by ancestry groups are further discussed below. Interpretation of the coefficients for ANC1*IM-ANC5*IM by themselves indicates only how the earnings of immigrants of each of these five ancestry categories compares with the earnings of immigrants of Western European ancestry. For the U.S. as a whole, all are significantly negative, indicating that, ceteris paribus, immigrants of all ancestry groups earn significantly less than Western European immigrants.

The central questions of this study, however, can not be answered by examining the coefficients in Table 3. One such question is whether or not the pattern of relative earnings of immigrants is significantly different across regions. The first step in answering this question is to determine whether the regional earnings functions differ significantly from the aggregated earnings function for the U.S. For this purpose, each of the regional regressions was subjected to a Chow test in order to determine if that earnings function differed significantly from the U.S. regression. ${ }^{10}$ All eight regions yielded F-ratios that were highly significant, ranging from 14.28 to 86.74 . The critical F-ratio for significance at the 0.01 significance level is a maximum of 1.87, indicating that every region's earnings function is significantly different from that for the nation as a whole.

The possibility exists that the finding of statistically significantly different regional earnings functions is a consequence of differences across regions in occupational and industrial mix. To investigate this possibility, Equation 1 was reestimated for the U.S. and each region with the addition of dummy variables representing four occupational categories and seven industry categories. The resulting earnings functions were again subjected to Chow tests. Once again, the F-ratios all were above the critical value for the 0.01 level of significance, and they ranged from 11.18 to $74.50 . .^{11}$ Partial F-tests indicate that the occupational and industry sets of dummies, both alone and together, were statistically significant at the 0.0001 level. Adjusted $R^{2}$ improved an average of 0.04 with the addition of these sets of variables, suggesting that at least a part of the difference across regions in earnings functions is attributable to regional differences in occupation and industry mix. Nonetheless, regional earnings patterns are still highly distinct from each other after controlling for the mix.

A second central question is whether or not immigrants have significantly lower earnings than native-born individuals of the same ethnic ancestry, region by

\footnotetext{
${ }^{10}$ In our case, the separate equations compared by means of the Chow test were one equation for a specific region and one for the U.S. excluding that region.

11 For economy of space the regressions with the occupational and regional dummies are not presented here, but are obtainable from the authors.
} 
region. To begin to answer that question, we have used the results of Table 3 to estimate the ratio of immigrant to nonimmigrant earnings within each region for each of the six ancestry groups. We have estimated both immigrant and native earnings using each region's regression coefficients applied to an assumed set of independent variable values. The assumed set is derived from the mean values for immigrants given in Table 2. For example, immigrants are assumed to be 40.8 years of age, with 16.3 of those years coming after immigration and 24.5 coming before. Nonimmigrants are assumed to be the same age as the immigrants. Within each region, incomes are estimated separately for each ethnic ancestry group. Thus, for each ethnic ancestry group within each region, a ratio of immigrant to nonimmigrant earnings can be estimated, with all demographic characteristics the same between immigrants and nonimmigrants except for those concerning immigrant status. Moreover, the same average demographic characteristics are used (the U.S. immigrant average) regardless of the region, thus maximizing comparability across region and ancestry categories. Such relative earnings ratios are reported in Table 4 as Earnings Ratio A. Stated otherwise:

$$
\text { Earnings Ratio } \mathrm{A}_{\mathrm{i}=0,5}=\frac{\left[\text { Pr edicted } \mathrm{IE}_{\mathrm{i}=0,5}\right]}{\text { Pr edicted } \left.\mathrm{NE}_{\mathrm{i}=0,5}\right]} \text {, }
$$

where Predicted $\mathrm{IE}_{\mathrm{i}}$ within each region is the average earnings predicted for immigrants in ancestry category $i$, as explained above, and Predicted $\mathrm{NE}_{\mathrm{i}}$ is the average earnings predicted for nonimmigrants of the same ancestry.

As can be seen from Table 4, Western European immigrants in the U.S. as a whole have earnings on average that are the same as native-born Americans of Western European ancestry, as indicated by the earnings ratio of 1.00. But when examined by region, all of the Earnings Ratio A estimates for Western Europeans differ from 1.00. Indeed, all of the Earnings Ratio A values in Table 4 differ from 1.00 save the first. To determine whether the remaining Earnings Ratio A estimates are statistically significantly different from 1.00 , a simple t-test was performed. The $t$-test involved whether the earnings estimation in the numerator differs significantly from that in the denominator, which is equivalent to a test that the ratio differs from 1.00. Owing to the very large sizes of each region's samples, all $t$ ratios are very large, ranging from a low of 7.35 for the Eastern Europeans in the Southwest, to a high of 133.32 for Hispanics in the Pacific region. The critical $t$ value for significance at the 0.001 level is in no case higher than 3.37. Thus, we can conclude that immigrants' earnings are different from the earnings of nativeborn individuals of the same ancestry in all regions and across all ancestry groups except one.

Examining the cross-regional variations in Earnings Ratio A for each ancestry group, it is the Arabic ancestry immigrants whose relative earnings vary most, and the African ancestry immigrants whose relative income varies the least. One can also examine, within each region, the variation in Earnings Ratio A across ancestry groups. In this comparison, it is Florida that exhibits the greatest variation, and the Mountain-Plains region for which Earnings Ratio A varies the least. 
Two other earnings ratios are calculated in order to provide the reader additional perspective on the results for Earnings Ratio A (the earnings of immigrants relative to native born of the same ancestry). These are reported in Table 4 as Earnings Ratio B and Earnings Ratio C. Earnings Ratio B is the estimated earnings of immigrants of each respective ancestry group relative to Western European immigrants with the same demographic characteristics. In other words, Earnings Ratio B is a recalculation of Earnings Ratio A but with the denominator indicating the predicted earnings of nonimmigrants of Western European ancestry with otherwise

TABLE 4

Earnings Ratios by Region of Ancestry and Region of Residence

\begin{tabular}{|c|c|c|c|c|c|c|}
\hline & $\begin{array}{l}\text { Western } \\
\text { Europe }\end{array}$ & $\begin{array}{l}\text { Eastern } \\
\text { Europe } \\
\end{array}$ & Hispanic & African & Arabic & Asian \\
\hline \multicolumn{7}{|l|}{ U.S. } \\
\hline Earnings Ratio A & 1.00 & 0.84 & 0.73 & 0.91 & 0.84 & 0.79 \\
\hline Earnings Ratio B & 1.00 & 0.90 & 0.72 & 0.77 & 0.88 & 0.82 \\
\hline Earnings Ratio C & 1 & 1.07 & 0.99 & 0.85 & 1.05 & 1.04 \\
\hline \multicolumn{7}{|c|}{ New York-New Jersey } \\
\hline Earnings Ratio A & 0.96 & 0.79 & 0.67 & 0.84 & 0.74 & 0.68 \\
\hline Earnings Ratio B & 0.96 & 0.83 & 0.69 & 0.74 & 0.83 & 0.74 \\
\hline Earnings Ratio C & 1 & 1.05 & 1.03 & 0.88 & 1.12 & 1.09 \\
\hline \multicolumn{7}{|l|}{ Northeast } \\
\hline Earnings Ratio A & 0.98 & 0.94 & 0.74 & 0.86 & 0.89 & 0.87 \\
\hline Earnings Ratio B & 0.98 & 0.94 & 0.78 & 0.78 & 0.90 & 0.78 \\
\hline Earnings Ratio $\mathrm{C}$ & 1 & 1.00 & 1.05 & 0.91 & 1.01 & 0.90 \\
\hline \multicolumn{7}{|l|}{ Midwest } \\
\hline Earnings Ratio A & 0.93 & 0.78 & 0.73 & 0.86 & 0.81 & 0.77 \\
\hline Earnings Ratio B & 0.93 & 0.82 & 0.72 & 0.78 & 0.76 & 0.80 \\
\hline Earnings Ratio C & 1 & 1.05 & 0.99 & 0.91 & 0.94 & 1.04 \\
\hline \multicolumn{7}{|l|}{ Florida } \\
\hline Earnings Ratio A & 0.93 & 1.13 & 0.83 & 0.90 & 0.89 & 0.78 \\
\hline Earnings Ratio B & 0.93 & 0.99 & 0.80 & 0.79 & 0.90 & 0.86 \\
\hline Earnings Ratio C & 1 & 0.88 & 0.96 & 0.88 & 1.01 & 1.10 \\
\hline \multicolumn{7}{|l|}{ Southeast } \\
\hline Earnings Ratio A & 1.06 & 0.88 & 0.88 & 0.85 & 0.92 & 0.85 \\
\hline Earnings Ratio B & 1.06 & 0.92 & 0.86 & 0.68 & 0.93 & 0.87 \\
\hline Earnings Ratio $\mathrm{C}$ & 1 & 1.05 & 0.92 & 0.80 & 0.81 & 1.02 \\
\hline \multicolumn{7}{|l|}{ Southwest } \\
\hline Earnings Ratio A & 1.18 & 1.03 & 0.77 & 0.85 & 1.25 & 0.96 \\
\hline Earnings Ratio B & 1.18 & 1.08 & 0.71 & 0.70 & 1.01 & 0.94 \\
\hline Earnings Ratio C & 1 & 1.05 & 0.92 & 0.82 & 0.81 & 0.99 \\
\hline \multicolumn{7}{|l|}{ Mountain-Plains } \\
\hline Earnings Ratio A & 0.92 & 0.84 & 0.75 & 0.92 & 0.69 & 0.79 \\
\hline Earnings Ratio B & 0.92 & 0.87 & 0.71 & 0.77 & 0.79 & 0.78 \\
\hline Earnings Ratio C & 1 & 1.04 & 0.95 & 0.84 & 1.14 & 0.99 \\
\hline \multicolumn{7}{|l|}{ Pacific } \\
\hline Earnings Ratio A & 0.95 & 0.79 & 0.70 & 0.93 & 0.77 & 0.79 \\
\hline Earnings Ratio B & 0.95 & 0.90 & 0.69 & 0.81 & 0.87 & 0.77 \\
\hline Earnings Ratio C & 1 & 1.14 & 0.99 & 0.87 & 1.13 & 0.97 \\
\hline
\end{tabular}


the same assumed independent variable values as explained above for the calculation of Earnings Ratio A. Thus, within each region:

$$
\text { Earnings Ratio } \mathrm{B}=\frac{\left[\text { Pr edicted } \mathrm{IE}_{\mathrm{i}=0,5}\right]}{\left[\text { Pr edicted } \mathrm{NE}_{\mathrm{i}=0}\right]},
$$

where Predicted $\mathrm{NE}_{\mathrm{i}=0}$ is, within each region, the predicted earnings of nonimmigrants of Western European ancestry. For additional perspective, Table 4 also provides the predicted earnings within each region of nonimmigrants of each ancestry group relative to otherwise comparable nonimmigrants of the majority group, those of Western European ancestry. This relative earnings ratio is identified as Earnings Ratio C, such that:

$$
\text { Earnings Ratio } \mathrm{C}=\frac{\left[\text { Predicted } \mathrm{NE}_{\mathrm{i}=0,5}\right]}{\left[\text { Predicted } \mathrm{NE}_{\mathrm{i}=0}\right]} \text {. }
$$

Examining Equations 2, 3, and 4, it can be seen that, by definition:

$$
\text { Earnings Ratio } \mathrm{C}=\frac{\text { Earnings Ratio B }}{\text { Earnings Ratio A }} \text {. }
$$

As with Earnings Ratio A, Earnings Ratio B values were subjected to a t-test. All ratios were significantly different from 1.00 at the 0.001 level or better ${ }^{12}$ except the ratio of 1.01 for Arabic ancestry in the Southwest. The consideration of the three ratios together yields some interesting results. For example, examination of Earnings Ratio B for the U.S. as a whole reveals that Hispanic and African ancestry individuals fare the worst of the ancestry groups relative to native-born Americans of Western European origin. ${ }^{13}$ But the earnings disadvantage of African ancestry immigrants is associated more with their being black and less with being an immigrant, as seen by comparing Earnings Ratios A and C. By contrast, Earnings Ratio $\mathrm{C}$ for Hispanics is nearly unity, indicating that virtually all of the earnings disadvantage of Hispanic immigrants (relative to natives of Western European ancestry) is associated with being an immigrant and not per se with being Hispanic.

The difference in the experiences of African and Hispanic immigrants perhaps may be explained as follows. Most Hispanic nonimmigrants speak English well; it is probably the case that many speak only English. Hence they are probably well assimilated into U.S. labor markets and suffer relatively little discrimination. But most Hispanic immigrants do not speak English well, often not at all, and previous research indicates that their earnings suffer as a result. ${ }^{14}$ On the other hand, previous research also indicates that American-born blacks continue to experience substantially lower earnings than demographically comparable

\footnotetext{
${ }^{12}$ No test of significance was applied to Earnings Ratio C estimates as these were calculated from the definitional identity given in Equation 5.

${ }_{13}$ Note, however, that this generalization breaks down when the regions are considered separately.

${ }^{14}$ The consequence for relative earnings of variations in English language ability is documented in McManus (1985). Carliner (1995) notes that in 1990, among Mexican immigrants ages 18-64, slightly over half spoke English "not well" or "not at all." For the same age group of native Americans of Mexican ancestry, only about 5 percent spoke English "not well" or "not at all." About 37 percent spoke only English.
} 
whites, even though this earnings differential has significantly decreased with each of the last several censuses. ${ }^{15}$ But, excepting Haitians, most immigrants of African origin arrive in the U.S. already speaking English, hence their immigrant status has a small marginal effect.

The comparison of the experience of Hispanic and African ancestry individuals is merely an illustrative example of the interpretation of the information in Table 4. A detailed discussion of the numerous other comparisons that could be made would be quite lengthy and not the main purpose of this research.

The primary purpose of this investigation was to determine if regional variation exists in the relative earnings patterns of various immigrant groups, and the results reported verify the existence of significant regional differences. The next task is to determine the extent to which the pattern of relative earnings of immigrants within and across regions presented in Table 4 is attributable to differences between immigrants and natives in their occupation and industry mixes. To accomplish this task, Earnings Ratio A was recalculated using the regression equations that included the occupation and industry dummy variables. ${ }^{16}$ For the U.S. as a whole, Earnings Ratio A for all ethnic groups increased and was significantly different from 1.00 . Within the separate regions, 30 earnings ratios were brought closer to 1.00 than they were in Table 4, while 2 were unchanged and 16 were farther from 1.00. Most changes were small, but one was quite large: Earnings Ratio A for Arabic ancestry individuals in the Southwest was reduced to approximately 1.00 from the 1.25 reported in Table 4 . Hence, the large difference in earnings between Arabic immigrants and natives in this region is virtually entirely attributable to the immigrants being more concentrated in the higher-paying occupations and industries. Interestingly, the one other ratio brought to approximately 1.00 was for Arabic ancestry immigrants in the Southeast. All of the remaining 46 recalculated Earnings Ratio A values are significantly different from 1.00 , with t-ratios ranging from 8.60 to $209.60 .{ }^{17}$ However, Arabic ancestry individuals remain the immigrant group with the most variation in relative earnings across regions.

\section{CONCLUSION}

The main purpose of this study was to document the extent of regional variation in the earnings of immigrants relative to both native-born Americans of the same ancestry and to the majority group of native-born Americans, those of Western European origin. Table 4 indicates that, for the most part, these variations are statistically significant and are not trivial in magnitude. This study used a larger number of regions and a larger number of ethnic ancestry categories than is typical of the literature on this topic. Nonetheless, an important caveat to the results presented here is that the disaggregation employed here may not have gone far

\footnotetext{
${ }^{15}$ See Smith and Welch (1989) and Bellante and Kogut (1996).

${ }^{16}$ In all these recalculations, the mean values for the occupation and industry dummies were those of immigrants for the U.S. as a whole. These mean values as well as the recalculated values for Earnings Ratio A are available from the authors.

${ }^{17}$ As with Table 4, the highest critical t-ratio for significance at the 0.001 level is 3.37 .
} 
enough. Take, for example, the fact that, as indicated by Earnings Ratio B, immigrants of Asian ancestry in the New York-New Jersey area earn about 74 percent of what comparable native-born Americans of Western European origin earn, whereas in the Southwest, the same relative earnings figure is 94 percent. Since the area of the world to which the Census Bureau attaches this ancestry label is large, the group is quite heterogeneous. Hence, without a finer breakdown of ancestry, the degree to which the difference between the New York-New Jersey and Southwest relative earnings is the result of this heterogeneity is not apparent. A finer breakdown of ethnicity is in fact provided by the Census, so the question is researchable, as would be the same potential question regarding the other ancestry categories. This observation suggests the desirability of further research that examines regional earnings differentials for one specific broad ancestry category, but separately examines the finer breakdown of geographical ancestry that is possible. Moreover, an analysis of a U.S. region that separately examines the states in that region might well reveal that our disaggregation into eight regions actually hides a material degree of intraregional variation.

While exploration of such matters is beyond the scope of this study, other researchers may find them worthy of investigation. If so, they can be confident that there are indeed regional differences to be explained. As long as immigrants tend to be geographically concentrated within the U.S., the earnings performance of immigrants will remain a significant issue in regional analysis.

\section{REFERENCES}

Bartel, Ann P., and Marianne J. Koch. "Internal Migration of U.S. Immigrants." In John M. Abowd and Richard B. Freeman (eds.) Immigration, Trade, and the Labor Market, 21-134. Chicago: University of Chicago, 1991.

Bellante, Don, and Carl A. Kogut. "Intra-Regional Wage Variation and Regional Disparity in the Relative Earnings of Blacks." Journal of Economics and Finance 20 (1996), 15-31.

Borjas, George J. "Review of Julian Simon, The Economic Consequences of Immigration." Journal of Economic Literature 29 (1991), 115-16.

"Assimilation and Changes in Cohort Quality Revisited: What Happened to Immigrant Earnings in the 1990s?" National Bureau of Economic Research Working Paper No. 4866. Cambridge, MA, 1994a.

"The Economics of Immigration." Journal of Economic Literature 32 (1994b), 1667-1717.

. "Reply to Julian Simon's Rejoinder." Journal of Economic Literature 34 (1996), 1332-33.

Carliner, Geoffrey. "The Language Ability of U.S. Immigrants: Assimilation and Cohort Effects." National Bureau of Economic Research Working Paper No. 5222. Cambridge, MA, 1995.

Daneshvary, Nasser. "Earnings Differentials between Natives and Immigrants with College Degree." The American Economist 37 (1993), 46-52. 
Daneshvary, Nasser, and William L. Weber. "Sources of Wage Differentials between Native and Immigrant Workers: A Regional Analysis." Review of Regional Studies 21 (1991), 119-35.

Dunlevy, James A. "On the Settlement Patterns of Recent Caribbean and Latin Immigrants to the United States." Growth and Change 22 (1991), 54-67.

McManus, Walter. "Labor Market Costs of Language Disparity: An Interpretation of Hispanic Earnings Differences." American Economic Review 75 (1985), 818-27.

Simon, Julian L. The Economic Consequences of Immigration. Cambridge, MA: Blackwell, 1989.

. "Reply to Review by George Borjas." Journal of Economic Literature 34 (1996), 1331-32.

Smith, James P., and Finis R. Welch. "Black Economic Progress After Myrdal." Journal of Economic Literature 27 (1989), 519-64.

Zavodny, Madeline. "Determinants of Recent Immigrants' Locational Choices." Federal Reserve Bank of Atlanta Working Paper No. 98-3. Atlanta, 1998. 